\title{
A Discourse on the Application of Linguistic to Teaching of College English Reading
}

\author{
Na Li \\ Xi’an International University, Xi’an, Shanxi, 710077, China
}

Keywords: linguistics; teaching of College English Reading; application

\begin{abstract}
Verbal communication is of great significance in the era of knowledge-driven economy. English as a universal language has also been enhanced and strengthened in China in college English reading instruction and it is one of the key points in teaching English Reading. Essentially, analyzing the teaching of English Reading from some aspects of the essence is one component of linguistics, so it's a very effective teaching method when combining the linguistics with teaching English reading, which is an immediate problem to be solved that how to connect linguistics to the teaching of College English Reading. Given this, the paper practically analyzes the current situation on College English Reading instruction based on the theory of linguistics to conduct a further reason for such situation, in this way, students can improve the ability of English Reading and teachers can enhance their teaching ability and the teaching quality.
\end{abstract}

\section{Introduction}

Reading has always been playing an important part in the language learning process and as one of accesses to the target language ${ }^{[1]}$ contains so many disciplines ${ }^{[2]}$. Therefore, grasping the rules of reading attaches great importance to learn English. University as a critical period of knowledge acquisition is quite important for students to improve the ability of reading and communication. The efficiency in English reading teaching directly affect the actual use of English. Therefore, English teachers should not only focus on improving the students' reading ability but also help them to master many useful skills during their reading teaching process.

Language as the most important means of communication of mankind is a direct implementation of people's thinking or ideas. There are four theoretical foundations within linguistics including psycho-linguistics, schema theory and lexis theory. Robin F. Goodman, a famous linguistic psychologist described that reading has been as a process of inference and guessing. He explained that learners should make summaries what they have learned or what information they have grasped in their reading process, according to the implementation of reading material or analyzed that by their own experience. In other words, readers need an actual situation to communicate with the author through textual materials. To put it simply, student is the subject of learning, so they'd better learn more about the cultures behind the language when they begin to learn a new language, by which they would deeply understand the reading material. ${ }^{[3]}$ According to the schema theory, reading is a complex process of synthetic knowledge interaction that readers combine vocabulary, syntactic and writing together and also an interaction of the previous knowledge and new information catcher form the material.

\section{The Present Situation on Teaching of College English Reading}

\subsection{Students' low reading literacy}

It is difficult for teachers to change the teaching models in a short time leading to students always passively accept knowledge or just followed teachers by intensively creaming learning. Teachers do not draw much attention to teaching students any correct reading ways or skills but just simply impart a pure way to gain knowledge. Consequently, students find it difficult to improve their reading ability juts as a Chinese proverb saying: giving a person by fish is inferior to give the 
person by fishing.

\subsection{Inappropriate reading strategies}

During the reading process, some teachers focus much on explaining language or knowledge points without any integrated-skill training on English reading strategies. Students do not know how to take different steps in a variety of reading materials or how to deal with different reading types or styles. Besides, they have no idea on when to flexibly choose a intensive reading, extensive reading or fast reading. Different features can be found in these three reading styles which are positively good for helping students improve their reading ability if such ways can be combined properly during the teaching process.

\subsection{Small reading volume}

A large amount of English reading volume can help a student to greatly promote their English standard. As a matter of fact, most of students are lack of reading quantity and were limited in a narrow confine, or they have little reading routines. Meanwhile, according to some researches, even lots of teachers didn't realize such kind of problems so that they take a wrong teaching key points for students. Consequently, students lose interest and lack of self-awareness on reading, leading to a restriction to improve their English reading level. ${ }^{[4]}$

There conclude the fallowing aspects after analyzing the above problems which related to the teaching models, teachers' ability and so on.

\section{Reasons for a Lower Teaching Quality}

\subsection{Teaching models}

In some specific process of English reading teaching, so many teachers would like to translate whole pages and then read out whatever types and modes of the text, through which students' initiative was difficult to be excited. In the case that teachers are still playing a leading part role in class, they do not focus on teaching students the ways of reading but too much on the contents during teaching process. Another reason concluded in the teaching models comes from the influence of the trend of examination education, both teachers and students ignore the final target of a reading task and they are quite overemphasizes on getting a right or wrong answer when doing reading exercise.

\subsection{English teachers}

English is no more than Chinese spreading based on its national cultures that reflects national connotations and beliefs in reality. Unfortunately, there are few students having accesses to acquire British and American cultures, which impeded students learn and understand well from the textbook. Most of college English teachers disregard the application of linguistic to teaching practical process. As so far, more and more researchers insist that linguistic is some how helpful to improve reading instruction.

\subsection{Teaching methods}

English teaching has always been emphasizing in China, while teaching points were attach little importance to teaching reading, for which the teaching efficiency was difficult to improve in majority of college English teaching. Students can not perfect in the discussion and communication of teaching or better use their skills because of teachers' stereotyped teaching concepts and methods. Whereas, more and more teaching practice turned out to be based on linguistics theories not only benefited to the foundation of language but also contribute to learning skills, so as to improve the ability of reading and communication of students. On the contrary, teachers did not realize the problem resulting in a lower teaching quality. 


\section{The Application of Linguistic to Teaching of College English Reading}

\subsection{To cultivate students to build a good reading habit}

During the reading process, teachers should always consider to develop a good reading habit which could reduce the teachers' burdens and help students to complete their reading task more effectively. On the one hand, teachers concerned much on the teaching quality. On the other hand, students have commonly formed bad reading habits. They cannot concentrate on a reading task but focus on the front paragraphs, even some of them tried to translate the whole passage when they were reading resulting in a low reading speed and quality.

In a case that in order to help students break up bad reading habits and flexibly master kinds of reading skills, the teacher tried different ways to applied in different reading materials. In his teaching process, he asked his students to catch details including the time, place, number, the important case, etc. even meet with words and sentences that he doesn't know or cannot understand. In the test, students was asked to collect the titles, the first and last sentence of paragraphs by fast reading which is great help in getting the skeleton and outline of the passage even they are in time pressure. Occasionally, students can go into more details and read up the whole passage by close reading when time permitted. The teacher hopes to students build a good reading habit in different situation in this way.

\subsection{To stimulate students' vocabulary}

The vocabulary is also quite important in linguistics. English reading ability is also related too much with one's volume of vocabulary in some ways. Generally, there is no problem in reading tasks if someone has a good command of large vocabulary about 3000 to 5000 .

For the sake of increasing students' vocabulary, a college English teacher orderly guided them to analyze long difficult sentences and derivative during reading process, through which students' independent learning ability can be improved. Helpfully, students strengthen their understanding, or extend to the synonymy and collocation after teachers' guidance.

\subsection{To focus on the application of linguistics}

Combining linguistics to English reading teaching attaches much importance on discourse and syntactic structure. To put it simply, when you read a passage, you should analyze each sentence on the perspective of thematic structure so as to understand the general idea effectively and fast to grasp the highlights of the passages as well. Students are required to take different approaches to deal with the connection of paragraphs which is considered in small parts linked up together and statements straightforwardly shown in the essay. Therefore, teachers need to list different requirements for students when fulfill a reading task according to kinds of types with different themes. ${ }^{[7]}$ Another way suggested in a reading task is to find out the topic sentence even it slightly differs from that in Chinese article. Mostly, there is always a topic sentence in each paragraph that students even can regard them as small passages. During the reading process, teachers can ask students to find out the topic or key sentence in each paragraph generally existing at the beginning and the end of the essay. This will not only make it clear for readers about the whole text structure but also promote one's reading speed.

When it comes to argumentation writings, a teacher asked students to try to use "you" "we" to follow the reading materials, through which readers would build a good relationship with the author, helping to get a well understanding the main idea of the essay. Particularly, the teacher courage students to guess the main idea of the essay when he set many questions related to the main idea. By discussing in groups, students can get a better understanding on material or the questions and also break the durance of the traditional method of reading.

\section{Conclusion}

In the current times, English reading teaching is not simple as one model but in need of a higher 
level combined with linguistics. Therefore, college English teachers should explore the regulation that linked to the teaching contents so that take full advantages of linguistics and arouse students' enthusiasm and initiative, at the same time, emphasizing on the application to good reading strategies. This will not only improve one's reading literacy but also accumulate the vocabulary, forming good reading habits.

\section{References}

[1] Xia Zhao, The Application of Linguistics to College English Reading Teaching, English Conner. 33(11): 94-95, 2012

[2] Wenxin Wang, Analyzing the Application of Linguistics to College English Reading Teaching, Education Times, 29 (21): 207, 2015

[3] Wanchun Wen, A Study on the Practice and Application of Linguistics to College English Reading Teaching, Campus English, 29 (09):85, 2016

[4] Jie Chen, Qiuxia Xu, The application of linguistics to the College English Reading Teaching Practice, Taiyuan City Vocational College, 37 (08):134-135, 2014.

[5] Mei Chou, The Function of linguistic in College English Reading Teaching, Knowledge Library, 23 (03): 57, 2015.

[6] Yanna Sui, Minhui Yao, A Brief Analyze of Linguistics Applied in College English Reading Teaching, Xue Lian, 51 (20) :94, 2015

[7] Jingyan Wang, The Application of Cognitive Linguistics to Vocational College English Reading Teaching, Nan Chang Teachers College Journal, 21 (h04) :133-134, 2010. 